\title{
Como discursos dominantes nos espaços da educação atravessam práticas docentes? ${ }^{1}$
}

\author{
Clarice Salete Traversini \& Caroline Stumpf Buaes \\ Universidade Federal do Rio Grande do Sul, Brasil
}

\begin{abstract}
Resumo
As práticas docentes são atravessadas pelos discursos dominantes em circulação nos espaços da educação na contemporaneidade. Nesse sentido, o artigo tem como objetivo analisar os discursos pedagógicos predominantes entre os professores quando se trata de metodologias de ensino. Para o estudo, selecionamos as noções de discurso pedagógico (Díaz, 1998), discutido a partir da compreensão de discurso de Michel Foucault. Para obtenção das informações, utilizamos questionários respondidos por 120 professores de escolas públicas e privadas de Santa Catarina e do Rio Grande do Sul, na região Sul do Brasil. As informações obtidas mostram que a interdição das metodologias centradas no ensino e o predomínio de uma pedagogia do aprendiz constituem o discurso pedagógico predominante na atualidade. Sommer (2005) e Silveira (2005) já apontavam tal predomínio ao estudarem os discursos sobre alfabetização. No entanto, não é apenas no que tange à alfabetização que tais discursos vigoram; eles também são encontrados nos ditos dos professores, tais como os de Educação Física e Letras, que atuam nas séries iniciais e finais do Ensino Fundamental e Médio.
\end{abstract}

Palavras-chave

Metodologias de ensino; Docência; Discursos pedagógicos

O presente artigo deriva da pesquisa Outros modos de olhar, outras palavras para ver e dizer, diferentes modos de ensinar e aprender: exercitando a docência na contemporaneidade. A investigação foi 
desenvolvida na Faculdade de Educação da Universidade Federal do Rio Grande do Sul (UFRGS-Brasil), no período de 2005 a 2007, e integra o Núcleo de Estudos sobre Currículo, Cultura e Sociedade (NECCSO). Objetiva analisar como os professores formados em Cursos de Licenciatura estão exercitando a docência no Ensino Fundamental e Médio na contemporaneidade, considerando os diferentes desafios do cotidiano escolar.

O interesse pela discussão emergiu por três razões: a) conhecer as ações docentes exercidas nas turmas nas quais atuam professores formados nos cursos de licenciatura; b) subsidiar as disciplinas ministradas nos Cursos de Graduação, pois os resultados da pesquisa aproximam os estudantes dos campos de atuação profissional criando meios de possibilitar que os universitários apropriem-se de saberes articulados com a realidade; c) discutir as representações docentes e discentes sobre metodologias de ensino e aprendizagem desenvolvidas nas escolas.

Para concretizar tal interesse, a investigação foi organizada em dois momentos: no primeiro, centramos nosso interesse em conhecer as representações dos alunos sobre atividades propostas que produziam ou não aprendizagem, envolvendo estudantes da rede pública e particular de Porto Alegre, estado do Rio Grande do Sul (Brasil), predominantemente de Ensino Fundamental e Médio. A leitura das informações coletadas possibilitou-nos dizer que: a) a mesma atividade foi classificada pelos alunos como geradora ou não de aprendizagem, dependendo da representação e do efeito da sua utilização no decorrer da experiência discente; b) o aluno reconhece uma atividade como "boa para aprender" quando ele consegue dar conta da tarefa proposta, e ao mesmo tempo se auto-reconhece como alguém competente e capaz, com condições de atingir sucesso na escola. Ambas as considerações mostram que, independente do tempo, do espaço e das condições de desenvolvimento das atividades propostas, não é possível vincular a metodologia desenvolvida a uma postura progressista ou conservadora do professor (Gore, 1995).

No segundo momento, buscamos conhecer as representações dos professores sobre metodologias de ensino e aprendizagem, particularmente no que tange as atividades por eles propostas. É sobre esse objetivo que se debruça o presente texto produzido a partir de uma pesquisa envolvendo as 
pesquisadoras e um grupo de acadêmicos que cursavam uma disciplina chamada Ensino e Identidade Docente, integrante dos seus cursos de licenciatura.

Aproximando noções dos Estudos Culturais com os estudos pósestruturalistas em educação agrupamos as informações obtidas e apresentamos algumas considerações a partir do estudo realizado. Este texto, então, está dividido em duas partes. Inicialmente, destacamos alguns conceitos que foram significativos nos diferentes momentos da investigação e o caminho metodológico percorrido. Na segunda parte, apresentamos alguns discursos pedagógicos recorrentes nas informações fornecidas pelos professores, quais sejam: a interdição das metodologias centradas no ensino e o predomínio de uma pedagogia do aprendiz.

\section{Dos caminhos que orientaram a investigação}

A pesquisa realizada da qual deriva este texto fundamenta-se teoricamente no campo dos Estudos Culturais. Para analisar as representações docentes sobre metodologias de ensino e aprendizagem desenvolvidas nas escolas utilizamos a noção de representação cultural discutida por em Hall (1997a, 1997b). Tal noção é compreendida não como um processo mental ou como um reflexo da realidade, buscando uma correspondência ideal, correta, verdadeira com as coisas do mundo. Essa noção de representação relaciona-se com as práticas de produção de significados, interessando sons, palavras, imagens ou conjunto de significantes por meio dos quais se produzem os significados em determinada cultura. A representação utiliza-se da linguagem para descrever o mundo que nos rodeia e, muitas vezes, ao fazer isso, acaba padronizando-o (Costa, 2002).

Compartilhamos da crença de que o conhecimento não é algo preexistente em algum lugar do mundo à espera para ser descoberto ou desvelado. A vontade de conhecer está imbricada com a vontade de poder (Foucault, 1996), portanto, o processo de conhecimento, do mesmo modo que a pesquisa e a escrita consiste em uma ação de nomear, atribuir sentido, caracterizar algo em determinado momento e espaço a partir de certa posição de poder (professor, pesquisador, escritor) e, por isso, autorizar a dizer algo 
que funciona como verdade. Dizer isso é considerar que o conhecimento produzido está situado temporal e historicamente e depende da linguagem que o produz. Desse modo, quando vinculamos as respostas dos professores pesquisados nesse ou naquele discurso pedagógico, o fazemos por meio de uma construção discursiva. No entanto, ao dizermos que "a realidade" é uma construção, "isso não quer dizer que não existe um mundo fora da linguagem mas sim que o acesso a esse mundo se dá pela significação mediada pela linguagem" (Costa, 2002: 107).

Nesse sentido, as metodologias utilizadas pelos professores para ensinar, na expectativa que produzam aprendizagens para os alunos e outras rechaçadas por não gerar tal efeito, adquirem sentidos validados por discursos pedagógicos vigentes e que adquirem um estatuto de verdade. Discurso é utilizado, neste estudo, a partir da compreensão que objetos e ações não se constituem naturalmente com seus nomes, mas é utilizando classificações e categorias da linguagem que os nomeamos. Conforme Foucault (1995), o discurso constitui-se de conjuntos de enunciados sustentados em formações discursivas que pertencem a um mesmo conjunto de regras e leis. Concebido assim, discurso consiste em uma prática ou conjunto de práticas que definem e formam os objetos de que falam, ou seja, são as palavras que fornecem significados às coisas. Portanto, é por meio de nomeações, descrições e concepções que construímos conhecimentos e podemos agir sobre nós mesmos e sobre os outros.

A partir dessa noção, Díaz (1998: 15) argumenta que o "discurso do professor não constitui um projeto deliberado de um falante autônomo a partir de uma intenção comunicativa", mas, continua o autor, "é assumido a partir de uma ordem, a partir de um sistema de produção do discurso, a partir de princípios de controle, seleção e exclusão que atuam sobre suas (re)produções de significados e sobre suas práticas especificas". Desse ponto de vista, o professor, considerado aqui como um sujeito pedagógico "é constituído, é formado e regulado, no discurso pedagógico, pela ordem, pelas posições e diferenças que esse discurso estabelece" (Díaz, 1998: 15).

Por sua vez, a formação docente é operacionalizada por um conjunto de discursos composto por textos, regras e práticas que pretendem assujeitar ou subjetivar $o$ indivíduo, interpelando-o a tornar-se determinado tipo professor: crítico, reflexivo, cooperativo, autônomo, automotivado, dentre 
tantos outros, como mostra Garcia (2002). Os discursos acerca da formação docente, por mais diferentes e variados que possam ser, "interpelam os sujeitos a fabricarem determinadas identidades para si mesmos" (Garcia, 2002: 139). Assim, nas instituições formadoras, nas políticas curriculares e de regulação da educação, no cotidiano das escolas, são validados discursos pedagógicos que mudam histórica e culturalmente.

Ao estudar metodologias de ensino, as entendemos como práticas pedagógicas operacionalizadas por meio de conjuntos de atividades escolares propostas pelos professores com vistas a alcançar a aprendizagem de determinados conhecimentos, valores e comportamentos. Significadas pela linguagem, as atividades escolares são classificadas como geradoras ou não de aprendizagem vinculadas a diferentes discursos pedagógicos conhecidos nos meios educacionais como tradicionais, tecnicistas e construtivistas, como mostra Diaz (1998) - dominantes em determinadas épocas, bem como relacionadas aos efeitos das experiências vivenciadas pelos professores e alunos como sujeitos e assujeitados pelas verdades instituídas nesses discursos pedagógicos.

Nesse sentido, a análise de Silveira (2005) sobre "os discursos dominantes existentes nas provas de ingresso para o magistério na rede pública" (p.1), em particular no campo discursivo da alfabetização e leitura, mostra que há embate de tendências pedagógicas, "cuja 'correção' pode variar de acordo com a hegemonia dos discursos que atravessam os distintos concursos públicos" (p.7). A autora sublinha o poder de tais discursos em "ratificar verdades pedagógicas e produzir o/a "professor/a de sucesso aquele que soube identificar, no momento exato, tais verdades". Na mesma perspectiva, a investigação de Sommer (2005) evidencia que "as práticas discursivas da escola obedecem a um ordenamento prévio, que os enunciados obedecem a regras de formação específicas, que alguns ditos são sancionados e outros interditados" (p. 4). Ainda, inspirado em Foucault (1996), o autor observa que "o que se diz na escola somente repercute porque é referendado por uma ordem mais ampla, porque está na ordem do discurso" (Sommer, 2005: 7).

Desde a década de 80, tendo como marco o evento $A$ Didática em Questão (Candau, 1984), realizado na Pontifícia Universidade Católica do Rio de Janeiro, em 1982, as pesquisas nos mostram que o processo de formação 
de professores não está centrado apenas no caráter prescritivo de como ensinar e como aprender e na reprodução dos conhecimentos tidos como universais para "dar boas aulas". As problematizações dos discursos pedagógicos trazidas por Sommer (2005), Silveira (2005), Diaz (1998), Garcia (2002) dentre outros, incita-nos a questionar que discursos priorizamos nos processos de formação de professores, que ordem do discurso pedagógico valorizamos e qual interditamos? Ao atuarmos nas faculdades de educação com formação de professores, podemos problematizar o já sabido, o praticado e o dito como professores e pesquisadores porque "já não podemos mais receber e aceitar conhecimentos, linguagens, formas de raciocínio, técnicas normativas, tipos de experiência da docência moderna...sem questioná-los" (Corazza, 2002: 59).

As noções teóricas selecionadas para este estudo inspiraram também o modo como coletamos as informações para serem analisadas. Silveira (2002), ao discutir um dos instrumentos utilizados nas pesquisas em educação - as entrevistas - mostra que são uma arena de significados. Compartilhando da perspectiva da autora, significamos desse modo também os questionários utilizados nesta pesquisa. Em outras palavras, consideramos que as respostas registradas pelos professores não trazem revelações íntimas ou estabelecimento de verdades. Assim como as entrevistas, os questionários são "embebidas[os] nos discursos de seu tempo, de situação vivida, das verdades instituídas para os grupos sociais dos membros dos grupos" (Silveira, 2002: 130).

\section{Obtenção e análise das informações}

As informações analisadas neste estudo foram obtidas em 2006, a partir de entrevistas ${ }^{2}$ (Silveira, 2002) realizadas com 120 professores de escolas municipais, estaduais e particulares de Santa Catarina e do Rio Grande do Sul, estados situados na região Sul do Brasil ${ }^{3}$. Os critérios utilizados para a seleção dos professores pesquisados na investigação proposta foram: facilidade de acesso das pesquisadoras, disponibilidade para fazer parte da pesquisa, ter cursado licenciatura e ter experiência docente.

Solicitamos aos participantes a resposta de perguntas abertas, quais sejam: a) No seu fazer pedagógico que atividades de ensino e aprendizagem 
são propostas aos alunos e considera que eles aprendem? Justifique; b) Em quais atividades propostas considerou que o aluno não aprendeu? Justifique.

As entrevistas foram analisadas a partir do referencial teórico dos Estudos Culturais, procurando encontrar representações recorrentes das atividades que geram ou não aprendizagem segundo os professores. Estas representações foram cotejadas com os discursos dominantes na atualidade no campo educacional. Desse processo emergiram duas unidades analíticas: A primeira denominamos $A$ interdição de metodologias centradas no ensino e a segunda $A$ pedagogia centrada no aprendiz.

Consideramos importante descrever alguns aspectos que caracterizam os participantes da pesquisa. Quanto a formação, a maior parte dos professores concluiu curso de licenciatura em instituições de Ensino Superior privadas da região. Dentre eles, há predomínio de docentes com Curso de Pedagogia e de Educação Física (80\%), em menor proporção, Licenciatura em Letras e em Matemática (13\%) e apenas um professor das Licenciaturas de Geografia, de História, de Filosofia e de Biologia (7\%). Todos os pesquisados cursavam Especialização na área da Educação. Em relação a experiência, os professores têm em média doze anos de atuação e aproximadamente $15 \%$ possuem apenas experiência de estágio realizado durante seu Curso de Licenciatura.

\section{A interdição de metodologias centradas no ensino}

Na questão sobre as atividades propostas pelos professores e que os alunos não aprendem, encontramos, num primeiro conjunto de respostas, aquelas consideradas "descontextualizadas", "sem significação", "repetitivas", "cansativas", "muito conteudistas", como podemos ler em alguns registros:

[...] atividades com assuntos que eles desconhecem, que está longe da realidade deles" (Prof. 45 ).

exercícios de fixação de normas e regras com repetição do exercício, ou cópia do que já foi feito (Prof. 53).

Quando você quer correr com o conteúdo dando bastante atividades, e as mesmas são propostas mais numa linha tradicional, o aluno cansa e acaba fazendo as atividades pela metade, não aprende e o professor vê o seu trabalho fracassado (Prof. 47).

Ficou perfeitamente claro que quando uso algumas atividades da cartilha as crianças não gostam e não aprendem pois fica muito distante da sua realidade (Prof. 59). 
As respostas aqui mencionadas podem ser classificadas no conjunto de discursos pedagógicos tradicionais, rechaçados no Brasil nos últimos 20 anos. Nesse aspecto é preciso considerar que o discurso construtivista, cuja acepção do aprender defende a ação do aluno sobre o objeto de aprendizagem, institui-se advogando pela ineficiência dos discursos tradicionais. Essa "força" do discurso construtivista torna-se visível pela oposição de método construtivista/tradicional, sendo o primeiro pólo significado como mais importante e por isso pode apresentar-se como uma verdade.

Guiadas pelos objetivos da pesquisa e pela questão investigativa se fez recorrente um segundo conjunto de respostas: aquelas que se referem a comunicação pouco clara do professor na sala de aula. Vejamos as respostas dos docentes:

Quando falo uma linguagem que não seja do entendimento do aluno, sinto que tenho que explicar de novo (Prof. 51).

Quando sinto que estou falando sozinho, sem diálogo, que não estão interagindo porque não estão entendendo (Prof. 90).

Parece que a comunicação pouco clara está vinculada ao distanciamento entre o conteúdo exposto pelo professor e as situações do cotidiano dos alunos, conforme exemplifica o professor:

Ao realizar uma atividade com uma poesia, a qual não tinha nada a ver com o cotidiano da criança, algo muito distante e pouco atraente para ela (Prof. 98).

Ainda, o uso excessivo de folhas reprografadas e livros didáticos podem prejudicar a clareza. Os materiais não explicados pelos professores, são utilizados, muitas vezes, sem um debate, sem entendimento do objetivo a ser alcançado, como mencionam as respostas a seguir:

[...] quando o professor distribui apostilas manda ler e apresentar. Não há envolvimento da turma. Fica monótono cansativo. É o fazer sem sentido (Prof. 65);

trabalhar só com livro ou material impresso, fica muito no abstrato, então fica mais difícil compreender (Prof. 81).

A análise das respostas nos remetem a Lulkin (2004) que chama atenção aos processos de ensinar e aprender. A nossa atenção precisa voltarse a um dos aspectos fundamentais na relação entre o sujeito que fala e o sujeito que escuta: "é a não-transparência da linguagem". O autor compartilha 
da compreensão de representação trazida por Silva (1999: 37), na qual, "o vínculo que se estabelece entre significante e significado é sempre resultado de uma construção social". Lulkin (2004: 44) chama atenção que ao assumir o uso da língua portuguesa (ou outra) em sala de aula como não sendo cristalina "é admitir que nem tudo o que 'eu' digo é compreendido como 'eu' gostaria, justamente porque os códigos são mediados pela cultura e cada um pode interpretar de maneira diversa o que está sendo dito, ainda que se busque sentidos comuns". Considerar a não-transparência da linguagem na proposição de atividades escolares e nos vocabulários utilizados por professores e alunos tem sido um indicativo para problematizar a efetivação do processo de ensino e da aprendizagem.

Há ainda um terceiro conjunto de registros que consideramos significativos para abordar, os quais já havia nos interessado nas análises preliminares:

Tudo gera aprendizagem (Prof. 52).

Sempre o aluno aprende algo (Prof. 70).

A resposta seguinte mereceu um olhar mais atento:

Não tenho lembrança [fazendo referência as atividades que considerava como não produtoras de aprendizagem] pois trabalhei há alguns anos como docente (Prof. 79).

Observamos que o Prof. 79 não atuava em 2006 em sala de aula, no entanto, já possuía experiência docente. Chamou-nos atenção que os professores 78 e 80 não responderam a questão, mas são professores que atuam em sala de aula e também têm experiência docente. Nas conversas informais com os professores pesquisados percebemos que eles lembram primeiro daquelas atividades que oferecem aos alunos e não geram aprendizagem do que ao contrário. Não responder a questão sobre as atividades improdutivas para aprender seria um indicativo que o professor não consegue identificar se a atividade produz alguns efeitos nos alunos? Tal questão é importante e precisa ser investigada com maior profundidade.

Merecem destaque, ainda, os seguintes registros dos professores afirmando que

[...] sempre o aluno aprende alguma coisa do que é ensinado (Prof.03). 
ou ainda,

[...] por mais frustrante que seja a aula para o professor, o aluno sempre aprende de uma forma ou outra o que foi planejado para aquele dia de aula (Prof. 33).

Nas análises preliminares, tais registros nos remeteram a uma leitura interpretativa que nos conduziu ao predomínio de uma representação que parece fortalecer a onipotência do professor quando se trata de ensinar e aprender. As leituras dos questionários realizados nos fez levantar outros questionamentos: sob um primeiro prisma podemos dizer que há uma "banalização" do termo aprendizagem, ou seja, qualquer atividade proposta pelo professor atinge o objetivo esperado: aprender algo, mesmo que seja, aprender a não "bagunçar" ocupando o tempo da aula com qualquer coisa. Ou então, situar como aprendizagem qualquer ação do aluno em relação a atividade proposta.

Sob um segundo prisma, localizamos os registros mencionados neste ultimo conjunto como pertencentes a um discurso apriorista, conforme denomina Becker (2000). Na descrição do autor, modelos pedagógicos e modelos epistemológicos embasados nos princípios aprioristas defendem que o aluno possui um conhecimento a priori, é o aluno que aprende por si. Nessa abordagem o professor é entendido como um auxiliar, que deve interferir o mínimo possível na aprendizagem do aluno, assim como sua crença é que: ninguém ensina ninguém. No presente texto não se está identificando quais discursos são os verdadeiros e que devem ser seguidos pelos professores para obter sucesso na escola. Nosso objetivo é propor algumas leituras e questionamentos acerca de alguns possíveis efeitos de tais discursos para as práticas pedagógicas na contemporaneidade e, principalmente, evidenciar quais discursos estamos validando nos processos de formação de professores.

\section{A pedagogia centrada no aprendiz}

As metodologias de ensino centradas no professor têm uma tênue entrada no rol dos discursos dominantes da educação. Os discursos pedagógicos dominantes na atualidade parecem evocar a pedagogia centrada no aprendiz. As respostas da questão acerca das atividades de 
ensino e aprendizagem propostas e que os professores indicam como produtivas para aprender foram organizadas em três agrupamentos, com ênfase: no aprender fazendo, na relação do conteúdo com a realidade do aluno e nas atividades com características lúdicas.

Quanto a ênfase no aprender fazendo, são mencionadas aquelas atividades que prevêem o uso de "materiais concretos" e que "trabalham a teoria na prática" como observamos em algumas das respostas:

Atividades relacionadas ao seu cotidiano com material concreto que instiga a curiosidade do educando [...] (Prof. 45).

Ao trabalhar com algo significativo, que faça parte do meio deles, como por exemplo: conhecer um pomar, colher frutas, estudar sobre suas utilidades, aproveitamento, fazer experiências na prática (Prof. 100).

As atividades que estão relacionadas com as práticas pedagógicas, pois conseguindo fazer a relação prática $X$ teoria transformaremos a realidade que está aí colocada (Prof. 69).

Os registros selecionados remetem ao que podemos chamar de ensino ativo, para usar a expressão de Popkewitz (2001): consiste em uma forma de desenvolver os raciocínios escolares por intermédio da proposição de atividades que lidam com a aprendizagem de conhecimentos classificados como "úteis" e "práticos". Como é uma metodologia que incentiva o "aprender fazendo", não diz respeito apenas ao conhecimento a ser aprendido, mas também ao "eu". Isso porque, nesse tipo de pensamento, o prazer e a participação não estão associados apenas ao que é aprendido, mas ao "fazer" para aprender (Popkewitz, 2001).

$\mathrm{Na}$ segunda ênfase, encontramos respostas que caracterizam como produtivas as atividades escolares propostas pelos professores para a aprendizagem dos alunos que relacionam o conteúdo escolar com a realidade do aluno:

[...] no trabalho que desenvolvi com jovens que freqüentam cursos profissionalizantes em técnicos agrícolas, no que se refere a aprendizagem, $o$ importante é partir da realidade de cada um. Assim o tema passa a ter sentido, a aula se torna mais atrativa, pois o assunto é de interesse (Prof. 92).

[...] são atividades do conhecimento cotidiano do aluno, ou seja, o conjunto de significados sobre a vida que nos rodeia (Prof. 111).

[...] depois de trabalhar o assunto água com a $3^{\text {a }}$ série este ano [2006], nós fomos conhecer a nascente do Rio do Mel, que abastece os municípios de 
Planalto e Alpestre e a CORSAN [empresa regional responsável pelo tratamento da água]. Assim partimos da teoria para a prática e houve 0 entendimento de todo o processo que a água passa e com certeza as crianças se conscientizaram da importância de preservar o meio ambiente (Prof. 58).

Partindo da classificação de Mizukami (1986), os registros selecionados referem-se ao que a autora denomina de abordagem sóciocultural, cujas características do processo de ensinar e aprender concentramse a superar a relação entre opressor-oprimido (cujo um dos entendimentos é o professor como opressor e o aluno como oprimido), desenvolvendo a consciência crítica por meio de práticas pedagógicas que valorizam o cotidiano do aluno e priorizam atividades com os chamados temas geradores. Nas práticas pedagógicas propostas principalmente para as crianças, após a década de 80 no Brasil, com a difusão das perspectivas construtivistas, a abordagem sócio-cultural tem se aliado com as metodologias ativas, discutidas anteriormente. Possivelmente, a aliança fortaleceu o argumento de que crianças, jovens e adultos "aprendem fazendo" e não "ouvindo" e nem realizando atividades "mecânicas". Com isso, as formas de ensinar e aprender não-centradas na atividade e no fazer do aluno são situadas como metodologias e seu uso não é recomendado.

O terceiro conjunto de registros acentuam como produtivas as atividades com características lúdicas, cuja ênfase recai nos jogos e brincadeiras, conforme as respostas que seguem:

[...] Atuando com crianças pequenas entendo que o fazer pedagógico jamais acontece desassociado de brincar. Ninguém ensina, ambos [professores e crianças] construímos conceitos e conhecimentos juntos (Prof. 97).

[...] Desenvolvo atividades lúdicas, jogos, teatros, expressões orais, trabalhos em grupo e atividades que o aluno precisa pensar, interagir e construir sua aprendizagem, sempre com a liberdade de criar, porém sob a orientação do professor que faz um papel de mediador entre o aluno e os saberes (Prof. 49).

[...] Trabalho de maneira lúdica, onde a participação da criança esteja interagindo a todo momento e fazendo com que a aprendizagem aconteça de forma divertida e prazerosa (Prof. 81).

A construção das práticas docentes parece estar mais relacionada com os discursos pedagógicos que atravessaram os professores na época da sua formação profissional do que com a área. Aqueles que tiveram sua formação a partir dos anos noventa, como os destacados acima, expressam uma 
identificação mais acentuada com os discursos que relacionam ludicidade $e$ aprendizagem. Se por um lado as atividades caracterizadas como tradicionais, tais como a repetição, a cópia, são tratadas como enfadonhas, cansativas e posicionadas como desinteressantes para os alunos, por outro, parece haver um imperativo do prazer para aprender. A partir dessa hipótese, o professor é concebido como alguém que orienta mais do que ensina, que prioriza o ritmo individual do aluno com possibilidade de haver diminuição de conteúdos trabalhados e que enfatiza a participação do aluno nas atividades de grupo. Essa "verdade" pedagógica centralizada no aprender lúdico é composta por um conjunto de discursos conhecidos no campo da Pedagogia, tais como "a Escola Nova, a pedagogia Freinet, o personalismo, as práticas rogerianas" (Palamidessi, 1996: 203).

Portanto, os registros mostram pouca ênfase nas metodologias de ensino centradas no professor. O centro do processo educativo escolar, nas últimas décadas, está no aluno, ou melhor, no seu processo de aprendizagem. Sommer (2005) evidencia essa centralidade do aluno e também o deslocamento da preocupação do ensino para a aprendizagem, nos discursos docentes sobre alfabetização. Também, nesta investigação com professores das Séries Iniciais, de Educação Física e um pequeno número que atuam nos Anos Finais do Ensino Fundamental e no Ensino Médio, tal discurso mantém sua vitalidade. Em outras palavras, os discursos pedagógicos construtivistas, dominantes nas últimas décadas, não produzem apenas a "pedagogia centrada na criança", como evidencia Walkerdine (1998), mas uma pedagogia centrada no aprendiz seja qual for sua faixa etária.

\section{Para finalizar... algumas "verdades" pedagógicas de nosso tempo}

A leitura das informações nos possibilitou perceber um predomínio do discurso pedagógico centrado na aprendizagem do aluno. Já atividades escolares que deixam de levar em conta os interesses dos alunos não aparecem mais nos registros dos professores, ou melhor são rechaçadas por eles. Situação essa que, anteriormente, na década de 80, ocupava a centralidade do discurso pedagógico da escola. Em resumo, para os professores questionados a aprendizagem ocorre desde que: a) sejam 
propostas atividades que o aluno aprenda fazendo; b) despertem o interesse e o prazer de aprender e; c) relacionem experiências anteriores, vivências pessoais e situações da "realidade" aos conteúdos a serem aprendidos. Já, as atividades desaconselhadas para produzir 0 aprender podem ser enumeradas como aquelas que não fazem relação com o contexto ou comunidade do aluno, repetitivas, cansativas e "conteudistas". Os professores também advertem para não fazer uso de uma linguagem distante daquela do aluno e evitar o uso excessivo de materiais didáticos.

$\mathrm{Na}$ leitura realizada, reconhecemos a importância e necessidade de oferecer atividades interessantes e acompanhar o seu desenvolvimento evidenciando o efeito na aprendizagem do aluno. Não advogamos aqui o retorno "saudosista" dos discursos pedagógicos classificados como tradicionais ou tecnicistas. Reconhecemos a importância de propor outras crenças no que tange a produção de diferentes formas de ensinar e aprender. No entanto, problematizamos a naturalização dos discursos pedagógicos predominantes, os quais classificamos como construtivista, sócio-cultural e lúdico, como redentores da aprendizagem do aluno e proféticos quanto a obtenção da desejada qualidade na educação.

As representações das práticas docentes interpelam os professores a assumirem posições de sujeitos e a partir delas são geradas práticas pedagógicas nas escolas. As narrativas dos participantes deste estudo expressam identificações com os discursos centrados no aluno. Segundo a nossa interpretação das informações, os discursos centrados no professor podem ter perdido a força, embora seja preciso considerar que eles coexistem. É nessa arena de significações que os professores parecem construir suas práticas docentes, atribuindo a elas uma multiplicidade de sentidos que não são possíveis capturar no momento da ação investigativa devido a sua dinamicidade e contingência.

Os resultados da pesquisa não nos fizeram problematizar apenas 0 contexto da escola e sim nos desafiaram a discutir também o discurso político educacional da atualidade. Silva (1998), Walkerdine (1998) e Palamidessi (1996) apontam que a universalização dos discursos centrados na aprendizagem do aluno, de predomínio construtivista, validados cientificamente, ao invés de promover a desejada cidadania e autonomia do aluno - como se sua aquisição ocorresse apenas na escola! — constituem- 
se em condições educacionais para viabilizar a racionalidade política em curso na contemporaneidade. Uma racionalidade caracterizada, tanto pela responsabilização do aluno pelo seu sucesso e fracasso escolar, quanto pela flexibilização regulada das políticas curriculares.

\section{Notas}

1 Uma versão inicial foi apresentada no $\mathrm{V}$ Congresso Internacional de Educação Pedagogia (entre) lugares e saberes, em São Leopoldo: UNISINOS:RS, de 20 a 22 de agosto de 2007. Agradecemos as sugestões produzidas durante o debate as quais foram incorporadas no artigo.

2 O Termo de Consentimento Informado assinado individualmente pelos professores está nos arquivos do grupo de pesquisa.

3 O número elevado de 120 entrevistas se deve ao interesse dos alunos em ter contato com o seu campo profissional. Nesse sentido, propusemos uma ação investigativa exploratória nas disciplinas que ministrávamos por considerá-la como um dispositivo pedagógico de formação docente. Portanto optamos por realizar a análise da totalidade dos dados coletados e discuti-los, tanto nos cursos de graduação quanto de extensão universitária.

$4 \mathrm{Na}$ abordagem sócio-cultural, compreende-se como tema gerador um assunto, um tema ou um problema da comunidade ou sociedade e em torno do qual desenvolvem-se um conjunto de conhecimentos afins, por meio de estudos, discussões e produção de saberes. Freire (1996) acentua a importância do processo de escolha desses assuntos, problemas ou temas geradores, pois eles não devem ser impostos. São resultado de ações mediadoras que incluem as responsabilidades docentes e os interesses dos alunos.

\section{Referências}

BECKER, Fernando (2000). A Epistemologia do Professor: o Cotidiano da Escola. 8. ed. Petrópolis: Vozes.

CANDAU, Vera Maria (1986). A Didática em Questão. Petrópolis: Vozes.

CORAZZA, Sandra Mara (2002). Pesquisa-ensino: o "hífen" da ligação necessária na formação docente. In M. T. Esteban \& E. Zaccur (Orgs.), ProfessoraPesquisadora - uma Práxis em Construção. Rio de Janeiro: DP\&A, pp. 55-70.

COSTA, Marisa C. V. (2002). Pesquisa-ação, pesquisa participativa e política cultural da identidade. In M. C. V. Costa (Org.), Caminhos Investigativos II: Outros Modos de Pensar e Fazer a Pesquisa em Educação. Rio de Janeiro: DP\&A, pp. 93-118.

DÍAZ, Mario (1998). Foucault, docentes e discursos pedagógicos. In T. T. Silva (Org.), Liberdades Reguladas: A Pedagogia Construtivista e Outras Formas de Governo do Eu. Petrópolis: Vozes. 
FOUCAULT, Michel (1996). Arqueologia do Saber. 4.ed. Rio de Janeiro: Forense Universitária.

FOUCAULT, Michel (1996). A Ordem do Discurso. Aula Inaugural no Collége de France, pronunciada em 2 de dezembro de 1970. 4.ed. São Paulo: Loyola.

FREIRE, Paulo (1996). Pedagogia da Autonomia: Saberes Necessários à Prática Docente. São Paulo: Paz e Terra.

GARCIA, Maria Manuela Alves (2002). A Docência no Discurso das Pedagogias Críticas.Tese de Mestrado em Educação. Porto Alegre: Universidade Federal do Rio Grande do Sul.

GORE, Jennifer M (1995). Foucault e a educação: fascinantes desafios. In T. T. Silva (Org.), O Sujeito da Educação: Estudos Foucaultianos. 2ªed.Petrópolis: Vozes.

HALL, Stuart (1997a) A centralidade da cultura: notas sobre as revoluções culturais do nosso tempo. Educação \& Realidade, v. 22, n.2, jul./dez, pp.15-46.

HALL, Stuart (1997b) The work of representation. In S. Hall (ed.), Representation: Cultural Representations and Signifying Practices. London: Sage/The Open University, pp. 13-74.

HYPOLITO, Álvaro M.; VIEIRA, Jarbas S. \& GARCIA, Maria M. (2002). Trabalho Docente: Formação e Identidades. Pelotas: Seiva, pp. 130-170.

LULKIN, Sérgio Andrés (2004). Conversa aberta com o professor. In J. Doll (Org.), Metodologia de Ensino em Foco: Práticas e Reflexões. Porto Alegre: Editora da UFRGS, pp.41-56.

MIZUKAMI, Maria das Graças N. (1986). Ensino: As Abordagens do Processo. São Paulo: EPU.

PALAMIDESSI, Mariano (1996). La producción del "maestro constructivista" en el discurso curricular. Educação \& Realidade, vol. 21, № 2, pp. 191-213.

POPKEWITZ, Thomas (2001). Lutando em Defesa da Alma: A Política do Ensino e a Construção do Professor. Porto Alegre: Artmed.

SILVA, Tomaz Tadeu da (1998). Liberdades reguladas: A Pedagogia Construtivista e Outras Formas de Governo do Eu. Petrópolis: Vozes.

SILVA, Tomaz Tadeu da (1999). O Currículo como Fetiche: A Poética e a Política do Texto Curricular. Belo Horizonte: Autêntica.

SILVEIRA, Rosa M. H. (2002). A entrevista em educação - uma arena de significados. In M. V. Costa (Org.), Caminhos investigativos II: Outros Modos de Pensar e Fazer Pesquisa em Educação. Rio de Janeiro: DP\&A, pp.119-141.

SILVEIRA, Rosa M. H. (2005). O que professoras/es do ensino fundamental "devem" saber sobre leitura e alfabetização? Uma análise de questões de concursos públicos. 28 $8^{\text {a }}$ Reunião Anual da ANPED. Caxambu (MG): ANPED. [Em linha] [Acesso em 01 de julho de 2006, disponível em http://www.anped.org.br/28/ textos/GT13/gt131437int.rtf]

SOMMER, Luis Henrique (2005). A ordem do discurso escolar. $28^{\text {a }}$ Reunião Anual da ANPED. Caxambú(MG): ANPED. [Em linha] [Acesso em 01 de julho de 2006, disponível em http://www.anped.org.br/28/textos /GT13/gt131037int.rtf.]

TRAVERSINI, Clarice Salete \& COSTA, Zuleika (2006). Formas de ensinar produzem o aprender? Comunicação apresentada no VI Seminário de Pesquisa em Educação da Região Sul, Santa Maria/RS: UFSM, 7 a 9 de Junho. 
WALKERDINE, Valerie (1998). Uma análise foucaultiana da pedagogia construtivista. In T. T. Silva (Org.), Liberdades Reguladas: A Pedagogia Construtivista e Outras Formas de Governo do Eu. Petrópolis: Vozes, pp. 143-216.

\title{
HOW DOMINANT DISCOURSES IN THE EDUCATION SPACE CROSS TEACHING PRACTICES?
}

\begin{abstract}
The teaching practices cross the dominant discourses in circulation in the education space today. This article aims at bringing about pedagogical discourses that prevail among teachers when they deal with teaching methodologies. For this study, we have selected the notions of pedagogical discourse (Díaz, 1998), as discussed from the comprehension of discourse of Michel Foucault. In order to obtain data, we have used questionnaires, which were answered by 120 teachers of both private and public schools in Santa Catarina and Rio Grande do Sul, southern Brazil. The information obtained has shown that the interdiction of methodologies centered on teaching, and the prevalence of learner pedagogy have constituted the currently prevailing pedagogical discourse. Sommer (2005) and Silveira (2005) had already pointed out this prevalence when they studied discourses about literacy. However, these discourses do not only appear in the field of literacy, but also in the discourse of teachers, such as those that teach Physical Education and Languages, that work with early and late grades of both Elementary and High School.
\end{abstract}

Keywords

Teaching methodologies; Teaching; Pedagogical discourses 


\section{CÓMO DISCURSOS DOMINANTES EN LOS ESPACIOS DE LA EDUCACIÓN ATRAVIESAN PRÁCTICAS DOCENTES?}

\section{Resumen}

Las prácticas docentes son atravesadas por los discursos dominantes en circulación en los espacios de la educación en la contemporaneidad. El artículo tiene como objetivo evidenciar los discursos pedagógicos predominantes entre los profesores cuando se trata de metodologías de enseñanza. Para el estudio, seleccionamos las nociones de discurso pedagógico (Díaz, 1998), discutido a partir de la comprensión de discurso de Michel Foucault. Para obtención de las informaciones, utilizamos cuestionarios contestados por 120 profesores de escuelas públicas y privadas de Santa Catarina y de Rio Grande do Sul, en la región Sur de Brasil. Las informaciones obtenidas muestran que la interdicción de las metodologías centradas en la enseñanza y el predominio de una pedagogía del aprendiente constituyen el discurso pedagógico predominante en la actualidad. Sommer (2005) y Silveira (2005) ya señalaban dicho predominio al estudiar los discursos sobre alfabetización. Sin embargo, no es solo en lo que tange a la alfabetización que tales discursos se fortalecen; también se encuentran en los dichos de los profesores, tales como los de Educación Física y Letras, que actúan en los años iniciales y finales de la Enseñanza Fundamental y Mediana.

Palabras-clave

Metodologías de enseñanza; Docencia; Discursos pedagógicos

Recebido em Setembro/2008 Aceite para publicação em Junho/2009

\footnotetext{
Toda a correspondência relativa a este artigo deve ser enviada para: Clarice Salete Traversini, Avenida Grécia, 1100 apartamento 1305, Bairro Passo d'Areia, CEP: 91350070, Porto Alegre, RS, Brasil.
} 